\title{
How do Europeans want to live in 2040? Citizen visions and their consequences for European land use
}

\author{
Marc J. Metzger ${ }^{1} \cdot$ Dave Murray-Rust $^{2} \cdot$ Joske Houtkamp $^{3} \cdot$ Anne Jensen $^{4}$. \\ Inge La Riviere ${ }^{3} \cdot$ James S. Paterson $^{1} \cdot$ Marta Pérez-Soba $^{3} \cdot$ Christiane Valluri-Nitsch $^{1}$
}

Received: 31 January 2016/Accepted: 4 December 2016/Published online: 12 January 2017

(c) The Author(s) 2017. This article is published with open access at Springerlink.com

\begin{abstract}
The aspirations, motivations and choices of individual European citizens are a major driver of the future of global, European and local land use. However, until now no land use study has explicitly attempted to find out how the general public wants to live in the future. This paper forms a first attempt to survey European citizens to understand their desired future lives in relation to consequences for European land use. We used a crowdsourcing experiment to elicit visions from young Europeans about their lives in 2040. Participants completed a graphic novel around carefully selected questions, allowing them to create a story of their imagined future lives in pictures. The methodology worked well, and the sample seemed reasonably representative albeit skewed towards an educated population. In total, 1131 responses from 29 countries were received. Results show a strong desire for change, and for
\end{abstract}

Electronic supplementary material The online version of this article (doi:10.1007/s10113-016-1091-3) contains supplementary material, which is available to authorized users.

\footnotetext{
Marc J. Metzger

marc.metzger@ed.ac.uk

Dave Murray-Rust

d.murray-rust@ed.ac.uk

Joske Houtkamp

joske.houtkamp@wur.nl

Anne Jensen

aj@envs.au.dk

Inge La Riviere

inge.lariviere@wur.nl

James S. Paterson

james.paterson@ed.ac.uk

Marta Pérez-Soba

marta.perezsoba@wur.nl
}

more sustainable lifestyles. There is desire for local and ecologically friendly food production, to eat less meat, to have access to green infrastructure and the ability to cycle to work. However, international travel remains popular, and the desire for extensive food production and owning detached houses with gardens will likely result in complex land use trade-offs. Future work could focus more specifically on quantifying these trade-offs and inform respondents about the consequences of their lifestyle choices. This was a first attempt to use crowdsourcing to understand citizen visions for their lives in the future, and our lessons learned will help future studies improve representativeness and increase responses.

Keywords Crowdsourcing · Visions · Scenarios · Land use $\cdot$ European citizens $\cdot$ Citizen science
Christiane Valluri-Nitsch

c.k.f.valluri-nitsch@sms.ed.ac.uk

1 School of GeoSciences, The University of Edinburgh, Drummond St., Edinburgh EH8 9XP, UK

2 School of Design, Edinburgh College of Art, 78 West Port, Edinburgh EH1 2LE, UK

3 Alterra, Wageningen UR, Droevendaalsesteeg 3, 6708 PB Wageningen, The Netherlands

4 Department of Environmental Sciences, Aarhus University, Frederiksborgvej 399, 4000 Roskilde, Denmark 


\section{Introduction}

Land system science has made major progress in understanding land use change (Rounsevell et al. 2012) and has highlighted the need to manage natural capital to ensure a continued provision of ecosystem services (Bateman et al. 2013; Lawler et al. 2014), including climate regulation (Stone 2009), sustainable food provision (Branca et al. 2013; Harvey and Pilgrim 2011; Smith 2013) and the preservation of our cultural (Beilin et al. 2014; Palomo et al. 2014) and natural heritage (Gimona et al. 2015). From this research we know we need to reduce our environmental footprint (Gerbens-Leenes and Nonhebel 2002; Hoekstra and Wiedmann 2014), and that individual citizens will play a major role in this (Bin and Dowlatabadi 2005; Vandenbergh and Steinemann 2007), e.g. by adopting a flexitarian (low-meat) or vegetarian diet (de Boer et al. 2006; de Vries and de Boer 2010; Pimentel and Pimentel 2003; Westhoek et al. 2014), reducing air travel (Gössling and Peeters 2007; Lee et al. 2001), and adopting energy efficient technologies (Chu and Majumdar 2012). We also know that other lifestyle choices significantly affect land use, including our willingness to pay for locally produced (Blake et al. 2010; Brown et al. 2009) or more extensively produced food (Padel and Foster 2005) and local green space or nature (Hofmann et al. 2012; Maraja et al. 2016; Tzoulas et al. 2007). In short, individual aspirations, motivations and choices are a major driver of future global, European and local land use.

Given this knowledge, it is surprising that comparatively little land use research has focused on obtaining a better understanding of individual citizens' desires for their future lives. There is a vast body of research focusing on lifestyle change in relation to recycling (Evans et al. 2013; Sachdeva et al. 2015), adopting low-carbon technologies (Skea and Nishioka 2008; Zapico et al. 2009), using public transport or bicycles (Aldred and Jungnickel 2014; Schwanen et al. 2012; Urry 2012) and changing diet (Mozaffarian et al. 2012). Market research has revealed how preferences can be influenced (Peloza et al. 2013), and paternalism and nudge theory (Thaler and Sunstein 2008; Scoccia 2013; Sunstein in press) describe how sustainable behaviour change can be promoted. In land use science agent-based models are used to incorporate individual agency in land management choices (Murray-Rust et al. 2014a), and assumptions about future consumer demand feature in explorative land use scenarios (Plieninger et al. 2013). More recently, normative approaches have looked at alternative visions for future land use in Europe in a facilitated stakeholder process (Pérez-Soba et al. 2015 , 2016). However, until now no land use study has explicitly attempted to find out how the general public wants to live in the future.
An understanding of individual desires and visions will allow identification of trade-offs and help to understand and anticipate where policy intervention may be required. Understanding differences between social, demographic and geographic groups would allow policy measures to be targeted. And comparisons between citizens' desires with policy or NGO visions will help assess legitimacy and support democratic voice in the land use debate. Developing this understanding is not a straightforward exercise, but forms a worthy research challenge that will not be easily resolved. There are major challenges in developing ways to engage citizens, enquire about their visions, interpret results and to ensure validity. This paper forms a first attempt to survey European citizens to understand their desired future lives in relation to consequences for European land use.

The European Union (EU) Biodiversity Strategy sets ambitious targets for conserving natural capital and ecosystem services (European Commission 2011). Although land use per se is not an EU competency, many of its strategies and policies (e.g. the Common Agricultural Policy, the Energy \& Forest strategies, 2030 framework for climate and energy TEN-T) directly affect land, and the benefits it provides to society. It is therefore of interest to gauge understanding of how European citizens want to live their lives, and how these visions would affect land use in Europe.

The EU comprises of 28 countries, over 500 million inhabitants, and 23 officially recognized languages. Engaging participants from this diverse and enormous target group with limited resources called for a creative web-based solution relying on voluntary contributions, i.e. a form of 'crowdsourcing'. In this paper, we describe and discuss our graphic novel-based approach, targeted at young Europeans (envisaged age between 16 and 30). We present an analysis of the 1131 responses, identifying similarities in visions and comparing citizens' visions to those developed by professional stakeholders. Despite a sample bias towards an educated population, we were able to identify and discuss a number of societal challenges for future land use planning and management in Europe and share lessons learned to support future research.

\section{Eliciting European Citizen visions}

\section{Design}

\section{A web-based graphic novel approach}

The aim of this study was to collect responses from young Europeans about their visions for their lives in 2040. Crowdsourcing provides an excellent means for eliciting 
responses from large numbers. While there are no universally accepted definitions, and a lot of discussion about what constitutes crowdsourcing (Estelles-Arolas and González-Ladrón-de-Guevara 2012), authors such Kazai (2011) focus on an open call for an undefined population to carry out tasks. Some definitions also include the idea that the tasks being done were previously done by experts (Howe 2008), as we intend here, following a crowdvoting approach (Estelles-Arolas and González-Ladrón-de-Guevara 2012) to elicit a range of preferences and opinion. Because the target group of young Europeans is accustomed to visual and interactive media, a visually appealing interface is an important requirement for the design of the crowdsourcing application. We selected the style of a graphic novel/comic book, allowing users to create a story of their imagined future lives in pictures.

The exercise is designed around filling in 'canvasses' (see Fig. 1), screens which focus on one aspect of life, and ask land use-related questions. The canvasses are laid out in a graphic novel style, with a mixture of graphical and textual elements. For each question, the respondent is offered a range of representative images to choose from to give a quantified response, drawn by artists specialized in visual communication. An adjacent text box then allows for a more personal take to be added by the participant, giving a space to voice desires that cannot be represented in a closed set of images. This pairing allows us to do a statistical analysis on the choice of images, but also perform textual analysis on the text entered. Murray-Rust et al. (2014b) provide a detailed description of the graphic novelbased approach, including discussing design choices and challenges in balancing the desire for open, creative behaviour against the time taken to complete the task and analysis constraints. Up to eight images were chosen per question to provide a choice of conventional and more aspirational responses, whilst allowing all images to be displayed on screen. Screenshots of the full experiment are included in Online Resource 1.

\section{Survey questions}

The crowdsourcing exercise embodied a survey around four aspects of everyday life, each represented in its own canvas: home; work; food; and free time. These aspects were chosen to embrace significant parts of life that also influence or rely on land management. In each canvas, we asked four questions about topics that directly affect land use, as detailed in Table 1.

Citizens' individual desires for the future are embedded in their societal vision for future land use. To deepen our understanding of citizens' desired lives, we therefore asked whether respondents agreed with eight broader statements related to land use in Europe:
1. We need local food and energy production to limit imports and transport costs.

2. Food production should be less intensive (e.g. organic) and more environmentally friendly.

3. Landscapes should change to offer more than one function: nature, food, forest and fun activities can be mixed in one area.

4. Productive land should focus on farming; less productive land can be used for other uses like nature.

5. We need a harmonious environmental policy throughout the whole of Europe.

6. Technology will help overcome most environmental, societal and economic problems.

7. Rural communities should receive financial support so that they remain attractive places to live.

8. Business and cultural activities should be encouraged in smaller towns and cities rather than large capital cities.

Finally, we asked the following personal socio-demographic details to support analysis of responses: age; education; income; employment; gender; current household composition; type of home they live in now; the closest green space to their current home; and they were asked to indicate their geographic location on a map.

Respondents were then presented with their graphic novel, collating their chosen images and written comments, and were given the opportunity to explore how their choices compared to other respondents (see Online Resource 1 for an example).

Due to resource constraints the survey could only be sent out in English.

An overview of all the images participants could select as answers to each question are provided in Online Resource 2.

\section{Testing}

As the application was designed specifically for this project, the interface and content contained many novel elements, such as the graphic novel metaphor, the interactive approach and the inquiries about the future visions. Any problems experienced during the use of an application would influence the quality of the answers and the engagement of the participants and might negatively affect the validity and quantity of results of the campaign. During the design phase, the development team therefore tested the usability and the appreciation of the interface, the clarity of the questions and the images with their descriptions. Important usability issues were first identified using a 'Think Aloud' method with four participants from the target group (Van den Haak et al. 2003). We then invited young people from across Europe, mainly students, to 


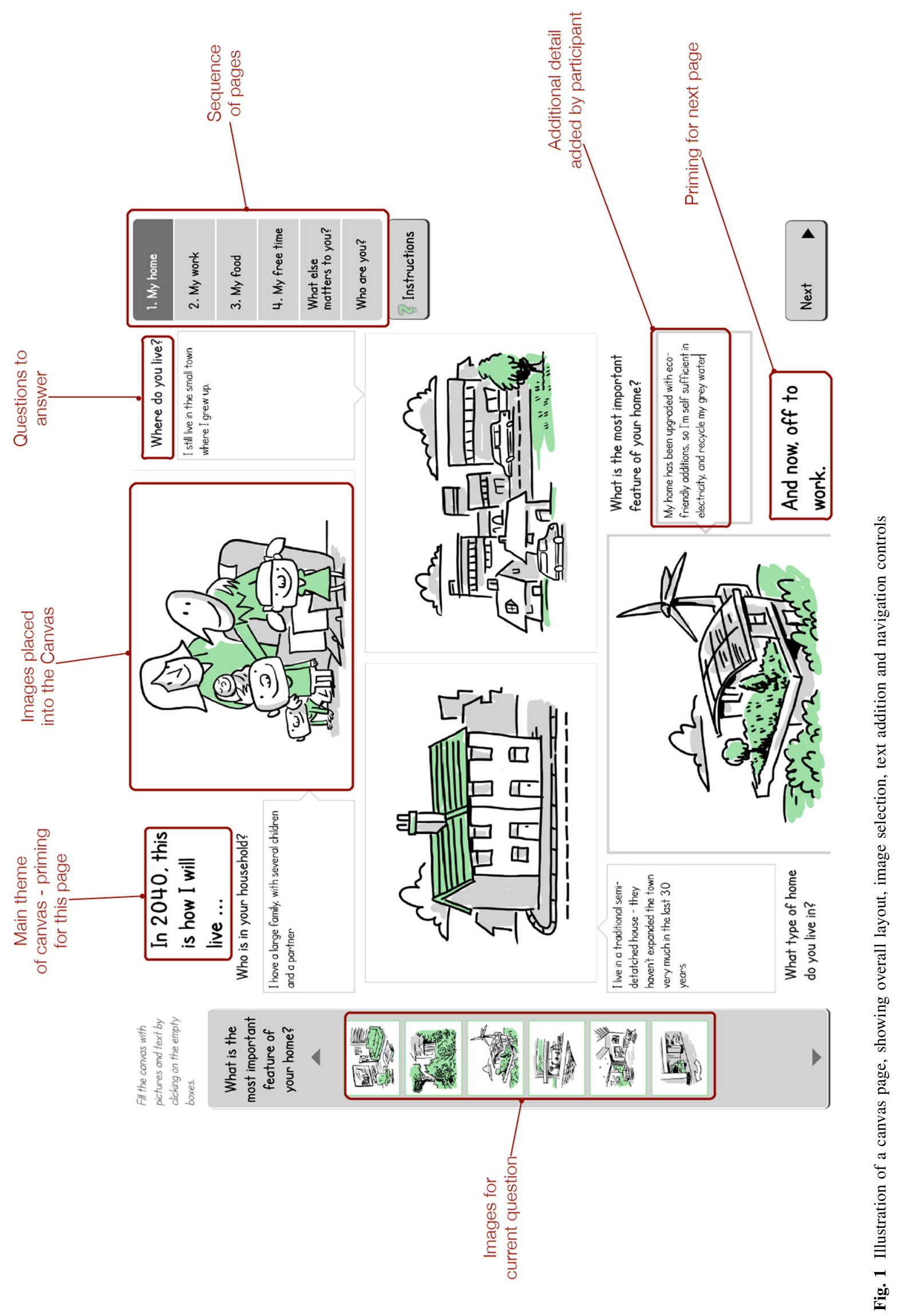


Table 1 Canvas questions, and rationale for inclusion, grouped around four aspects of life

\begin{tabular}{|c|c|c|}
\hline Canvas & Question & Rationale \\
\hline \multirow[t]{4}{*}{ My home } & Who is in your household? & $\begin{array}{l}\text { Shared or multi-occupancy households are more efficient use of resources } \\
\text { (space, energy) }\end{array}$ \\
\hline & Where do you live? & Will influence urban sprawl and rural regeneration and abandonment \\
\hline & What type of home do you live in? & Will determine extent of urban area \\
\hline & $\begin{array}{l}\text { What is the most important feature of your } \\
\text { home? }\end{array}$ & Gardens and spacious design affect extent \\
\hline \multirow[t]{4}{*}{ My work } & Which sector do you work in? & Gauges interest in primary sector \\
\hline & How do you get to work? & Influences transport infrastructure and energy demand \\
\hline & Where do you work? & Influences transport infrastructure and energy demand \\
\hline & $\begin{array}{l}\text { Does you job require frequent business-related } \\
\text { travel? }\end{array}$ & Influences transport infrastructure and energy demand \\
\hline \multirow[t]{4}{*}{ My food } & What food do you eat? & Flexitarian, vegetarian and vegan diets will reduce demands on land \\
\hline & Where do you prefer to buy your food? & Reflects demand for local food production \\
\hline & How is the majority of your food transported? & Influences energy demand and demand for local food production \\
\hline & How is your food produced? & Influence land use directly (e.g. extensive organic production) \\
\hline \multirow{4}{*}{$\begin{array}{l}\text { My free } \\
\text { time }\end{array}$} & How do you spend your leisure time? & Gauges interest in outdoors activities and nature \\
\hline & What do you do on holiday? & Gauges interest in outdoors activities and nature \\
\hline & What green space is close to your home? & Describes desired local green infrastructure \\
\hline & Where do you go on holiday? & Indicates energy demand \\
\hline
\end{tabular}

The images users could select as answers to each question are included in Online Resource 2

participate in an online pilot test. This test consisted of completing the exercise, plus answering 44 questions addressing the usability and attractiveness of the interface, and the clarity of the questions, answers and the statements. Forty participants from 11 countries completed the test. The results showed that the participants enjoyed filling in the canvasses; and in general they experienced few problems with the interface or understanding the texts. A number of usability and language issues emerged, for instance ambiguity of particular questions and answers, and clarity in the formulation of the statements. These were improved before the final version was launched.

\section{Data collection}

Crowdsourcing is convenience sampling methodology, with the strength to escape the sample of western, educated, industrialized, rich and democratic (WEIRD) participants (Henrich et al. 2010) and access hard-to-reach populations (Palmer and Strickland 2016). To initiate the campaign across the diverse geography of Europe, it was promoted through the personal and professional networks of 60 researchers in the VOLANTE research project and by contacting 350 individual stakeholders and 50 professional organizations, including youth groups and civil society NGOs. We envisaged these people would initiate a snowball effect, extending the sample beyond the potential reach of the researchers (cf snowball sampling; Noy 2008).
The campaign ran from 2 July 2014 to 17 June 2015 under the URL www.life2040.eu.

The website consisted of two parts: a flash-based frontend which the participants used to fill in the canvasses, and a database backend written in Scala/Lift which the experimenters could use to configure the canvasses and monitor the progress of the experiment. ${ }^{1}$ The software is configurable so that similar experiments with different questions and sets of images can be carried out in the future.

\section{Analysis}

\section{Respondent data}

The respondent data consist of:

- 16 image selections (which could be left blank) for the questions posed on the canvasses

- 16 free text comments associated with each of the questions (again, these could be left blank

- 7 image selections for demographic attributes: age, urban/rural location, education, gender etc.

- 8 statements, which could be included as being important to the respondent.

- Latitude/longitude data

${ }^{1}$ The backend and images are freely available at https://bitbucket. org/mo_seph/volante-crowdsourcing; the front end at https://bit bucket.org/wuralterra/flexclient. 
Unless indicated differently the analyses used the full dataset, which contains responses that are incomplete, i.e. one or more selections were omitted.

\section{Descriptive word frequency analysis}

Quantitative summative word frequency analysis (Hsieh and Shannon 2005) using NVivo (2012) software was used to find the five most common topics for each question and within each canvas theme. Commonly used words, including such as the, $a$, of and were eliminated using a 'stop word list' provided by NVivo. Synonyms such as bike and cycle were treated as identical in the analysis. When the meaning or context of the word was unclear, content analysis was used to understand its context. The analysis identified frequently discussed topics in the open text boxes of the canvas pages.

\section{Clustering}

Clustering was carried out to understand structures within the respondent population. Two different approaches were used: clustering by the respondents' current demographics and clustering using the images selected to portray their visions for the future. This allowed for comparison of respondents grouped by (i) current state and (ii) future desires. In each case, after the clusters were assigned, the proportions of all choices were calculated for each group, to highlight any structure, e.g. whether a demographically defined group had a common vision.

Partitioning around medoids (PAM; Kaufman \& Rousseeuw, 1990) — a variant of $k$-means clustering suitable for categorical data-was used. Details of this method can be found in Resource 3.

\section{Comparing citizen visions with expert visions}

Pérez-Soba et al. (2016) present three visions of European land use in 2040 based on an extensive stakeholder process with 69 experts from different land use sectors. These visions are: Best Land in Europe, which envisages optimal use of land resources; Regional Connected, where people live closer to the natural environment; and Local Multifunctional, which is centred around self-sufficiency of local communities. The visions are described in detail by Pérez-Soba et al. (2015). Here, we want to compare the citizens' visions with those developed by the land use experts.

To locate each response within the space of these visions, we constructed scores for how well their response related to each vision. Firstly, each of the images which could be selected was assigned (using moderated expert judgement) a score for whether they were strongly in line with the expert vision $(+2)$, in line $(+1)$, neutral $(0)$, contradictory $(-1)$ or strongly contradictory $(-2)$. Each respondent's image choices were then combined with the assigned vision scores to calculate an overall score for how well each respondent's image choices match each vision, ranging from -32 to 32 .

A similar process was carried out for the statement choices-each statement was assigned a score for each vision; the scores for all statements selected by each respondent were then totalled to give a separate statement score, ranging from -16 to 16 .

Since the scores for icons and statements were collected in a different manner and relate to different aspects of the person's vision (individual and societal desires, respectively), these scores were not combined, giving each respondent six scores-images and statements for three visions.

\section{Results}

\section{Respondent data}

In total, 1131 responses were received. Of these, 736 contained complete sets of choices for the canvas questions and demographic images. Summaries of the demographic attributes, question responses and the statements can be found in Fig. 2). Additionally, Fig. 3 shows the locations of the 396 respondents who provided a geographic location.

The results (Fig. 2a) show a good gender balance, and the predominantly urban response $(71 \%)$ corresponds with the $72 \%$ of EU citizens living in cities, towns and suburbs (Eurostat 2016a). And student responses (32\%) are in line with recent figures published that $37 \%$ of EU citizens between 30 and 34 have now completed tertiary education (Eurostat 2016b). However, the non-student population is skewed towards highly educated individuals (81\%) working in the quaternary sector $(39 \%)$. This is considerably higher than the EU average of around 30\%; Turečková and Martinát, 2015). Despite a geographic spread across 29 countries, a few countries are over-represented (e.g. The Netherlands).

Answers for My home are fairly conventional with $52 \%$ living with a small family or as a couple, although co-housing options with parent or other relatives were chosen by $13 \%$ of respondents. Many respondents still want to live in cities $(19 \%)$ or towns $(19 \%)$, but this is less than currently the case $(37 \%$ and $17 \%$, respectively). Detached houses $(31 \%)$ and gardens $(31 \%)$ clearly stand out as most desirable, though eco-friendly specifications are most important to $22 \%$ of respondents. 


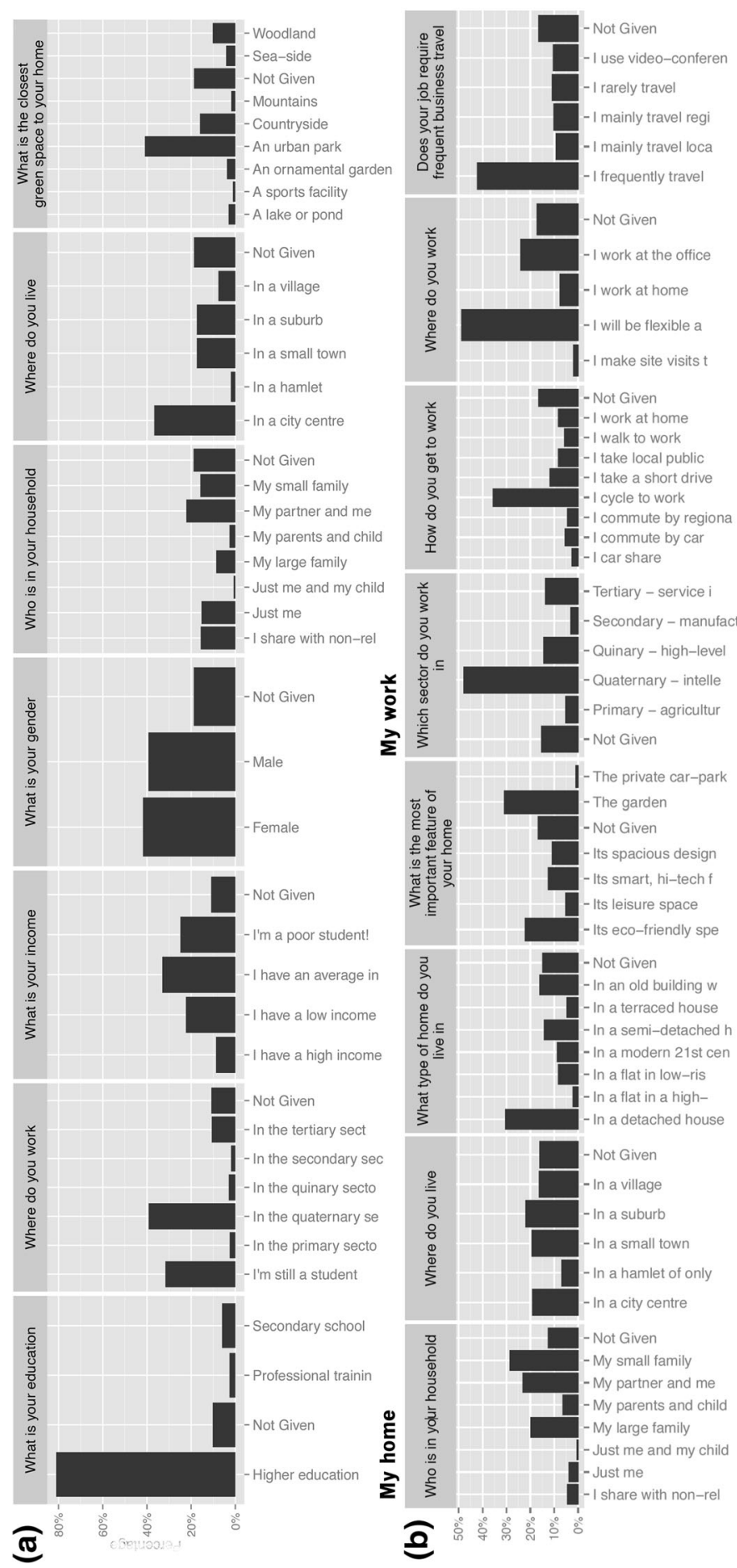

Fig. 2 Breakdown of a the demographic choices across the entire respondent population, $\mathbf{b}$ image choices for each of the 16 questions across the entire respondent population and c supported societal

The most popular choices for My work are to work in the quaternary sector $(48 \%)$ at a number of flexible locations (49\%), which you can get to on the bike $(36 \%)$ when not away for frequent work-related travel (42\%).

My food revealed that although the greatest group of respondents $(40 \%)$ will still eat anything, a flexitarian

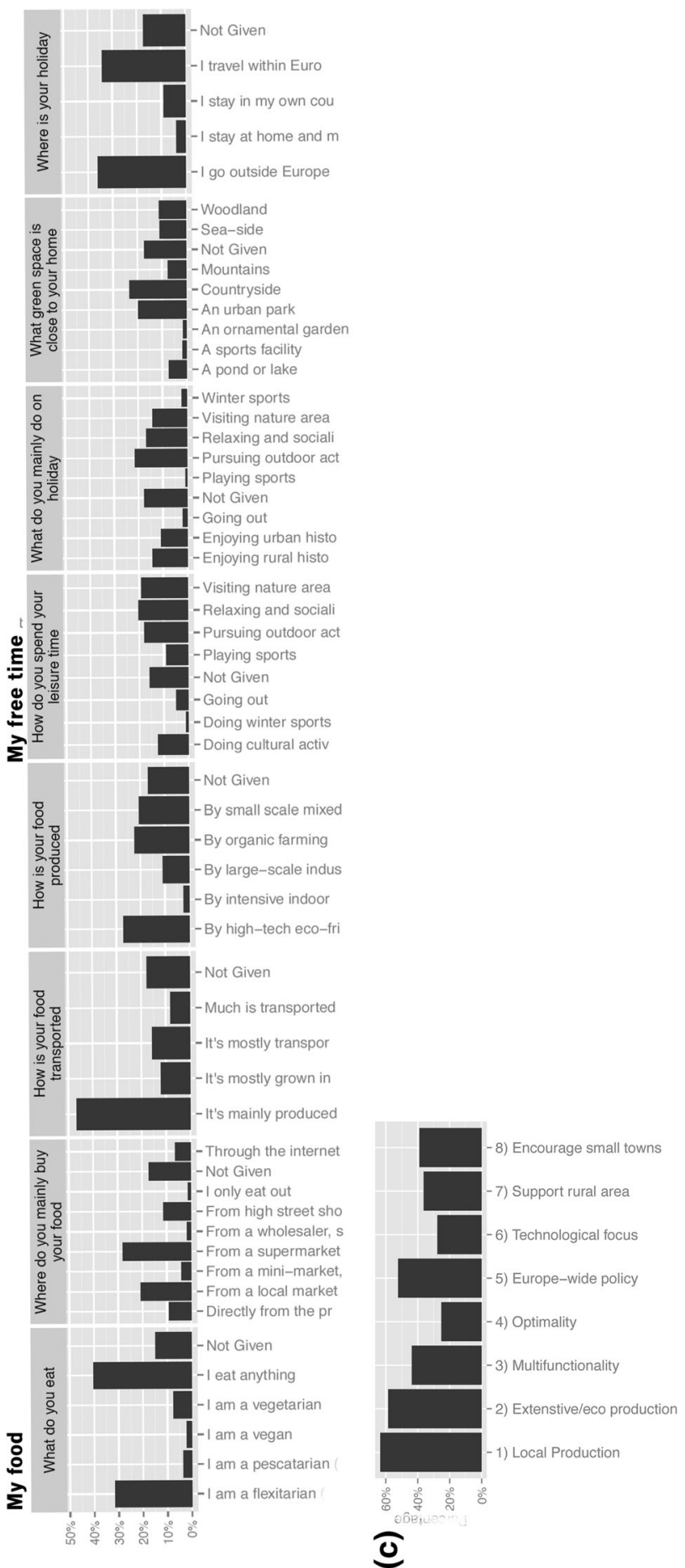

statements as percentage of respondents who selected a statement. The unlabelled bard indicates that no selection was made

diet with limited meat consumption is very popular $(32 \%)$. And although the majority would like to buy most of their food from a supermarket (28\%), local markets (21\%), high street shops (11\%) and buying directly from the producer $(9 \%)$ are popular. Ecofriendly precision agriculture is the preferred way of 


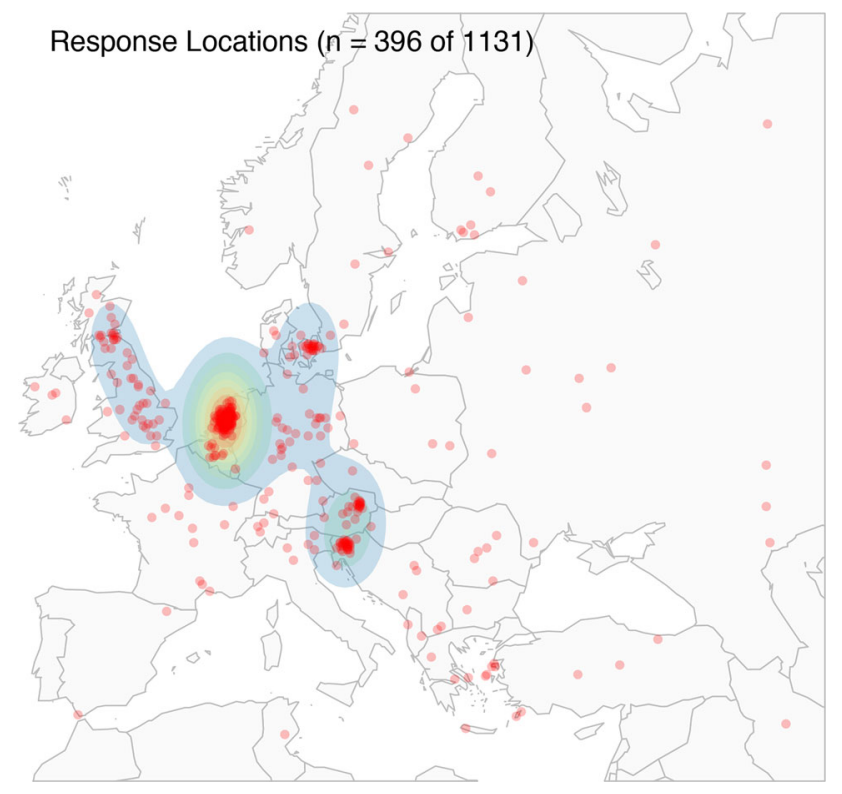

Fig. 3 Geographic distribution of the respondents

food production (27\%), with organic (22\%) and smallscale production $(20 \%)$ popular choices.

Relaxing and socializing (20\%), visiting nature areas (19\%) and pursuing outdoor activities (18\%) were all popular activities in the My free time canvas, with the latter the most popular holiday activity (21\%). Holidays outside Europe $(34 \%)$ are slightly more popular than staying in Europe $(30 \%)$, with only a minority choosing to stay in their own country $(13 \%)$.

The response to the statements (Fig. 2c) reveals great support for local production and consumption of food and energy (62\%), and less intensive production (59\%). Just over half (52\%) of the respondents support a harmonious European environmental policy. Optimally allocating land to its best use was least popular (23\%), followed by trust in technology to overcome environmental, societal and economic problems $(28 \%)$.

\section{Word frequency analysis}

Only 442 respondents completed one or more of the open text boxes, which could be used to elaborate a vision. Several dominant topics emerged from the word frequency analysis, which are elaborated per canvas theme. Table 2 provides a summary of the five most frequently mentioned terms per canvas, with more detail per question provided in Online Resource 4.

Similar to the closed questions responses, the word frequency results for My home are fairly conventional. Word counts revealed that 213 respondents see themselves living with a partner, 179 with children. Pets were mentioned 43 times, more frequently than co-housing (22).
Urban living was by far the most popular (city (138); city centre (37)). Towns, suburbs and villages were mentioned 63,51 and 45 times, respectively. The most frequently used words to describe desired homes were garden (57), detached (53) and flat or apartment (38). However, when asked about the most important feature of the home, the garden clearly stood out (134) followed by eco (51), and big (37).

The most popular career choices in the My work section are in research (57), consultancy (26), design (25) management (19). The dominant choice for cycling to work (274) is consistent with the image choices reported above, though public transport appears more popular (138), and cars are mentioned only 70 times. Contrasting with the images choices, the office remained the most popular location to work (91), with flexible work mentioned 41 times. Work travel was frequent (34) and necessary (25), including travel across Europe (21) and around the world (40).

Meat (90) was the most frequently used word in the $M y$ food canvas, mostly discussed in the context of eating less meat, and sometimes fish (24), that was sustainably and often locally produced. Many stick to a mixed diet, eating anything (78), but a vegetarian diet was mentioned by 24. Although supermarkets remain the most popular place to buy food (81), markets are not far off (77) and buying directly from the producers (43) is also popular. Local food transport was mentioned a lot, including home grown (51), and delivery by producers (37). Organic (61), eco (39) and hi-tech (32) were popular terms describing future food production.

In the My free time canvas sports (69), nature (45), play (42), relax (40) and cultural (29) were the most common word choices to describe leisure time activities. For holidays this changed to culture (47), relax (44), nature (38), sports (20) and history (19). Forests (41), countryside (20) and lakes (20) were the most commonly mentioned green space close to home. Europe was the most popular holiday destination (71) followed by world (56), whilst 31 opted to stay at home.

\section{Comparing citizen visions with expert visions}

Density plots for the three visions are given in Fig. 4a, based on the clean dataset $(n=736)$. Local Multifunctional (LM) corresponds most to the choices for both the image choices (46\%) and statements (72\%). Best land (BL) corresponds the least, receiving the highest score from just $25 \%$ by the image choices and $19 \%$ by the statement. The correlation between scores for each vision based on canvas answers and statement selection is plotted and presented in Online Resource 5. Although in each case the correlation is in the correct direction, the goodness of fit $\left(r^{2}\right.$, measured at $0.04,0.05$ and 0.13 ) is too low to be statistically significant. 
Table 2 Synthesis of descriptive word frequency analysis listing the five most frequent terms overall and per canvas

\begin{tabular}{|c|c|c|c|c|c|c|c|c|c|}
\hline \multicolumn{2}{|l|}{ Overall } & \multicolumn{2}{|l|}{ My home } & \multicolumn{2}{|l|}{ My work } & \multicolumn{2}{|l|}{ My food } & \multicolumn{2}{|c|}{ My free time } \\
\hline Keywords & Frequency & Keywords & Frequency & Keywords & Frequency & Keywords & Frequency & Keywords & Frequency \\
\hline Garden & 566 & Garden & 196 & Public transport & 158 & Farming & 134 & Nature & 101 \\
\hline City & 432 & City & 167 & Bike & 134 & Organic & 113 & Relax & 91 \\
\hline Nature & 298 & Children & 131 & Office & 119 & Supermarket & 102 & Cultural & 84 \\
\hline Children & 260 & Big & 108 & Research & 79 & Market & 95 & Sports & 94 \\
\hline Europe & 248 & Partner & 83 & Car & 76 & Meat & 90 & Europe & 75 \\
\hline
\end{tabular}

\section{Clustering}

When clustering was performed on the uncleaned data, in all cases there was a single cluster which was predominantly composed of responses with very little information (i.e. no answer given to most questions and demographic choices). However, removing all of the responses that missed any information is unfairly restrictive, as participants may reasonably feel uncomfortable providing some details, e.g. gender or socioeconomic status. As a result, we primarily considered the uncleaned dataset, but have removed the category consisting of primarily null responses from the presentation below. This allows partial responses to be counted, especially if they relate strongly to one of the non-null clusters, but avoids overanalysis of the low-quality results.

The silhouette of a point indicates how well it fits the cluster it is assigned to compared to the closest alternative; the average silhouette across a whole clustering gives an indication of its quality. Silhouette plots for this data are included as Online Resource 6 and indicate that there is no strong case for a particular value of $k$. We hence present results for $k=4$, giving us three clusters of good responses and one 'null' cluster. This also relates to the cardinality of three expert visions, allowing us to explore whether the clusters strongly relate to these visions.

\section{Clustering by answers to canvas questions}

The four clusters based on similarity in selected answers are described here, with full details available in Online Resource 7a.

Cluster $1(n=420)$ consists of people who want to travel within Europe for their holidays, do outdoor activities, visit nature and live near the countryside. They eat locally produced flexitarian food from small-scale farms, often bought directly from the producers, supplemented with home-grown produce. They will work flexibly, predominantly cycling to work and tend towards intellectual activities. They want to live in eco-friendly houses in small towns, often in low density or historic buildings. Demographically, they tend to currently be female, with an average income, living as a couple and have gone through higher education. When related to the consolidated visions, their responses show a clear preference ordering Local Multifunctionality (LM) $>$ Regional Connected (RC) $>$ Best Land in Europe (BL) (see Fig. 4b), which is mostly carried through to their selection of statements (although the preference for LM over RC is less clear).

Cluster $2(n=290)$ wants to holiday outside Europe and pursue outdoor activities. They also want to eat local food, but from high-tech eco-friendly farms, and are omnivorous. They will work flexibly, but with frequent global travel, and aspire to high-level decision-making. They will live with a small family, in a large house with a garden, in a village. Currently, this group comprises students, on low income. They have a similar relationship to the visions as Cluster 1 (Fig. 4b).

Cluster $3(n=186)$ is the 'null' cluster-in Online Resource 7a, every line shows far more than average 'null' responses and a lower than average proportion of all other responses.

Cluster $4(n=235)$ is urban, socializing at home and visiting nearby parks. They will shop in supermarkets, eating a wide range of food transported by road, produced by large-scale farming. They want to commute by car from the suburbs, where they live in high-tech houses, with large families. Currently, they are male students, living in the city centre or suburbs. They do not show a strong preference relationship with the visions, although in their statement selection they have least affinity for BL (Fig. 4b).

\section{Clustering by demographics}

The four clusters based on similarity in respondent demographics are described here, with full details available in Online Resource $7 \mathrm{~b}$.

Cluster $1(n=392)$ tends to be female students, living in the city and sharing their household with others. There is little structure in their desires, apart from a tendency towards a family and global travel. 


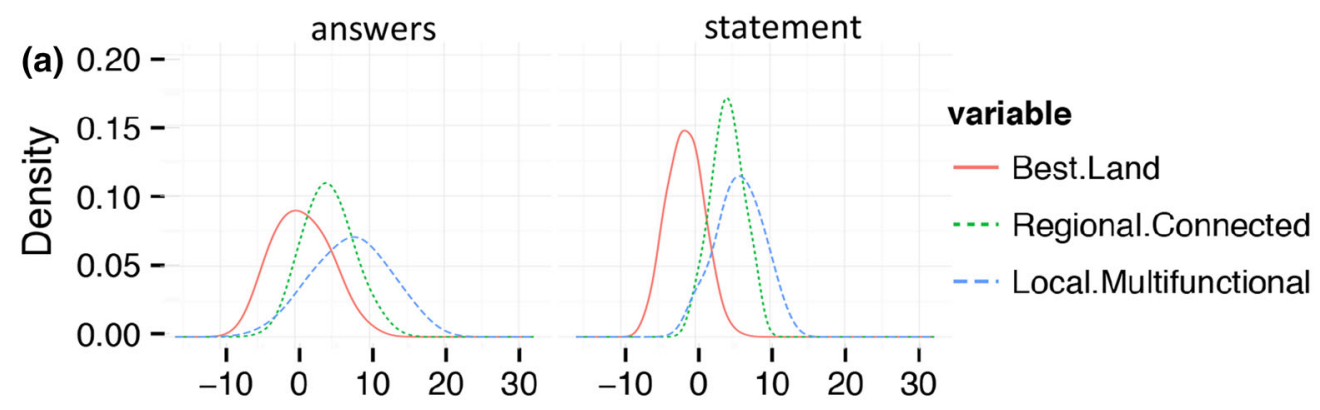

(b) $0.20-$

1

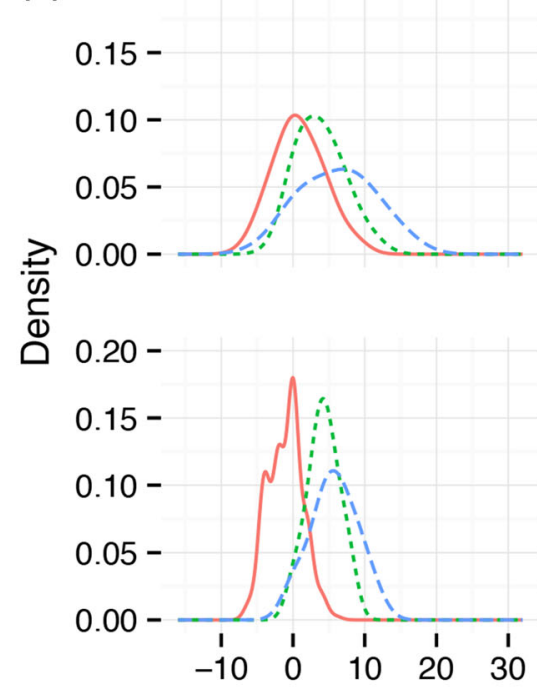

2
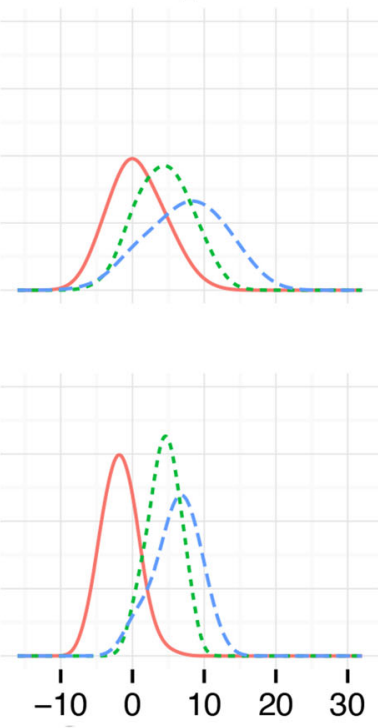

2

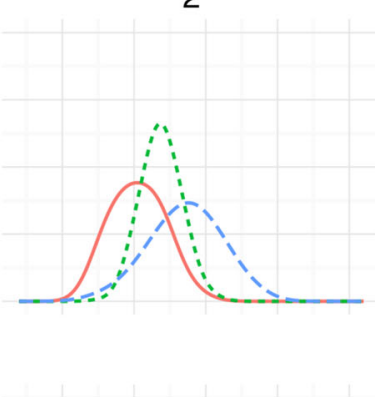

3

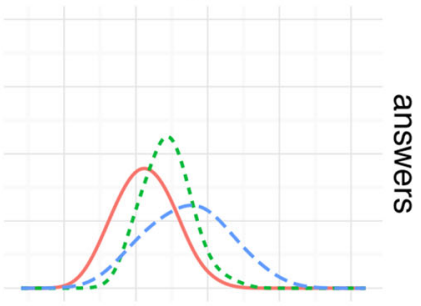

$\sum_{\frac{D}{0}}^{0}$

(c) 0.20 -

1
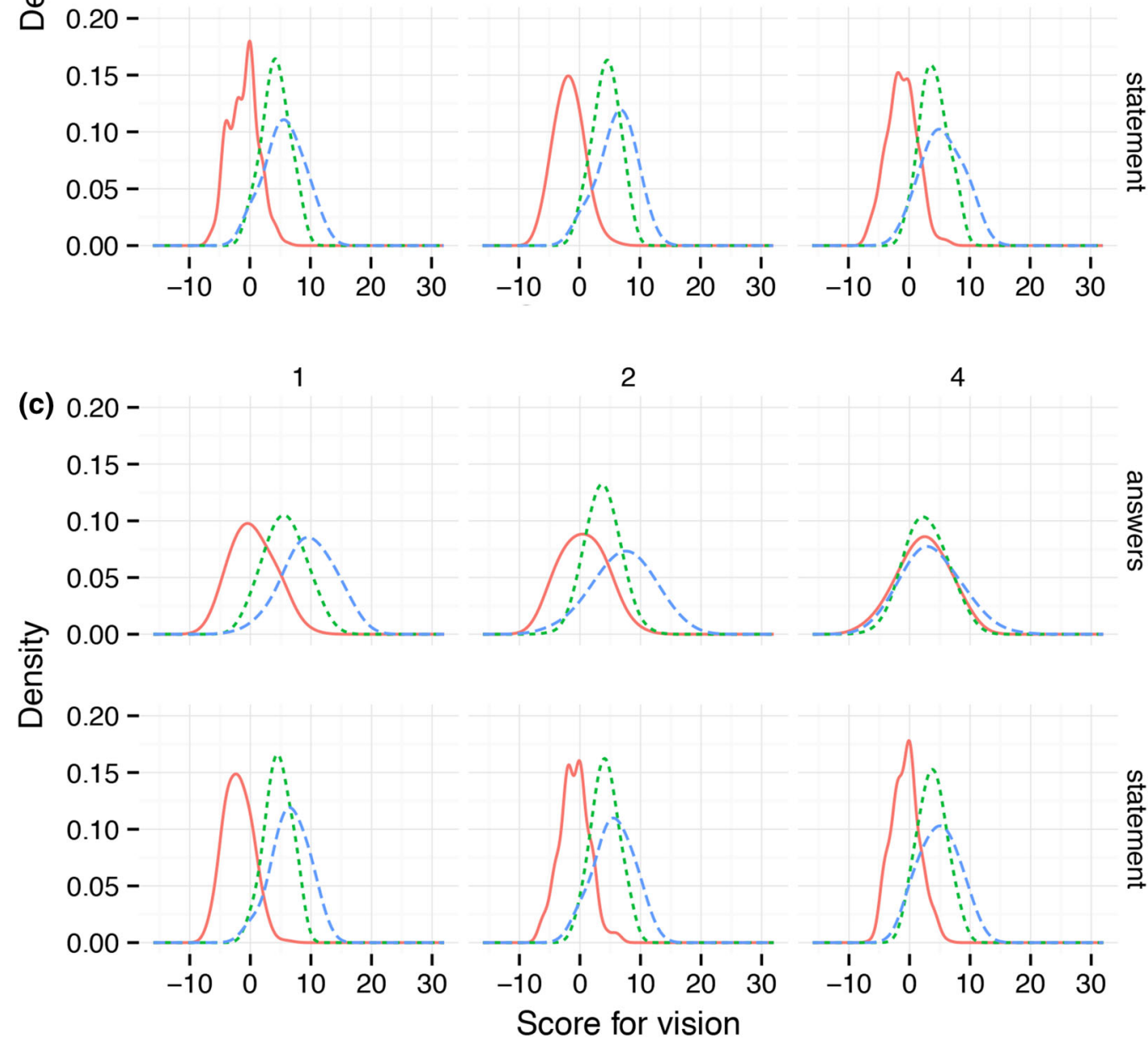



4
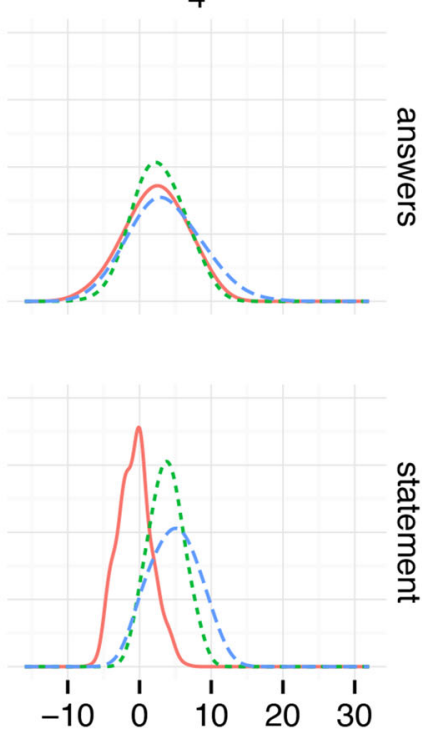

Fig. 4 Density plots of vision scores calculated for each respondent for the three expert visions described by Pérez-Soba et al. (2015): a show scores across the entire population of respondents; $\mathbf{b}$ for each of the clusters constructed from canvas image selections; and $\mathbf{c}$ for the three clustered

constructed from demographic information. The values on the $x$-axis reflect the scores, potentially ranging from -32 to +32 for the answers and -16 to +16 for the statements. The $y$-axis denotes the fraction of respondents assigning a score 
Cluster $2(n=340)$ is intellectual female city-dwellers, living as couples on average income from working in the quaternary sector. Their vision is for living as a couple, still in the quaternary sector but working flexibly. They eat flexitarian, locally produced food from small farms, visiting nature and pursuing outdoor activities.

Cluster 3 ( $n=188)$ is males with small families, living in the countryside on average or high incomes from intellectual work. Their vision is for gardens, detached houses in small towns and intellectual work carried out at home. They will eat anything and are not particularly fussy about where it comes from, and in their holidays they will visit the European countryside.

Cluster $4(n=211)$ was the 'null' cluster, with all questions showing a higher proportion of 'null' responses and a lower proportion of all other responses. It has a different size to the null cluster in the previous section as there are fewer demographic attributes, and more null responses within them, leading to a larger group of poor quality responses.

\section{Discussion}

\section{Methods}

Crowdsourcing is a growing research methodology (Dickinson et al. 2010). With limited resources, we were able to obtain 1131 responses from our diverse and geographically spread target group. Although there are biases in the sample of respondents, technically the experiment worked well and provides interesting results. The software developed for this experiment is flexible and could be adapted for other surveys where alternative choices can be expressed as visual images and a graphic novel would form a relevant incentive.

Despite user testing before the launch, we were surprised by some early responses. For example, many respondents did not select their geographic location on the map, and fewer participants than expected added text comments. We therefore decided to evaluate the experiment again, with 10 Dutch students and 20 students in vocational training, focusing specifically on usability and language issues that might affect participation as well as the validity of the answers. Whilst students in vocational training identified up to 20 words or sentences as difficult or confusing on the canvas pages, university students showed a good understanding. The evaluation allowed us to simplify some text and clarify instructions for the remaining period of the experiment.

Testing prior to the launch, informal feedback during the experiment, and the above-mentioned evaluation showed the experiment was generally well received by the target group, and the graphic novel liked. Academic, policy and land use stakeholders also showed a keen interest and helped distribute the survey. However, this positive reception was not sufficient to create a snowball effect that reached a more representative demographic. We suspect that the nature and the complexity of the topic probably limit uptake and willingness to share results and promote the survey, especially among young people in high school or vocational education. Possible solutions to increase participation include adding a games element to the experiment, or offering rewards or the possibility to win a prize. However, when local organizations actively promoted the survey response rates increased rapidly, causing geographical biases in the responses, but also demonstrating the value of targeted publicity and encouragement.

Our main advice for any future survey would be to develop a strong communication and marketing plan at an early stage in the research design-and allocate sufficient resources-to reach difficult target groups and ensure maximum uptake. Collaboration with European civil society and youth organizations, or the development of lesson or activity plans for schools and clubs would greatly improve the reach. Although a recent study found that $78 \%$ of 15-24-year-olds in Europe self-assessed their grasp of English as good or very good (EC 2012), translation into other languages would also be beneficial, especially to ensure an accessibility to young people with lower education levels. Furthermore, given the positive feedback about the creative and engaging format, the methodology may also be adapted as an innovative tool for more indepth semi-structured interviews to understand individual future visions.

\section{Results and implications}

The haphazard promotion of the experiment using academic and professional networks has resulted in a clear geographic bias around active colleagues, including co-authors in The Netherlands, Denmark and the UK. The method of promotion is also likely to have resulted in the over-representation of educated respondents, with $81 \%$ reporting a higher education, and $39 \%$ working in the quaternary sector. The EU average is about $30 \%$, but ranges from $20 \%$ (Lithuania) to $60 \%$ (Luxemburg), and in the over-represented countries mentioned before between $35 \%$ and $40 \%$ of the population works in the quaternary sector (Turečková and Martinát, 2015). Otherwise, the characteristics of the respondents, based on the questions asked in the survey, appear reasonably representative in comparison with EU summary statistics (see 'Respondent data' section).

The clusters of answers to the canvas questions (see 'Clustering' section) clearly distinguished a more 
conventional cluster (cluster 4; 235 respondents) reflecting current lifestyles that include conventional shopping and eating habits, living in suburbs and commuting by car. There is little in this cluster that points to a strong desire for a more sustainable lifestyle, or a substantial change in land use or land management. It is not surprising that this cluster does not show a strong relationship with the land use visions described by Pérez-Soba et al. $(2015,2016)$, which all envisage substantial change. By contrast, the vast majority of respondents fall in clusters $1(n=420)$ and 2 $(n=290)$ which describe lifestyles that would require substantial and possibly radical societal change.

Examples of responses that would result in substantial land use change include large changes in diet, with a majority indicating a desire to eat locally grown (59\%), organic $(22 \%)$ food produced by small-scale producers (20\%) and to reduce meat consumption (32\% flexitarian). These changes would have massive implications for food production, but also rural vitality, with $44 \%$ indicating they wish to live outside cities and towns, and $49 \%$ indicating a desire for flexible working at different locations, whilst ideally cycling to work (36\%). The word frequency analysis and responses to the societal statements show consistency with these results. The latter indicating support for local food and energy production (62\%), less intensive production $(59 \%)$ and harmonious European environmental policy $(52 \%)$. Although it is easy to refute the emerging caricature of future European land use as unrealistic or idealistic, they clearly paint a picture of a desired future land use that is very different from current trends.

The comparison with expert visions ('Comparing citizen visions with expert visions' section) should be treated with caution, as the participants were not shown these visions. The results show respondents did not like the BL vision, with its focus on optimal land allocation and efficiency. The LM expert vision received the highest scores, based on the popular responses in relation to local food production, cycling to work, living outside cities, and supporting multifunctional use and the rural areas. In the expert vision LM, this world of localism is achieved through radical behavioural change and governance shifts to local decision-making that were not explicitly included in the experiment. Contrary to the expert visions, respondents were not specifically asked to think of a sustainable future and the results therefore cannot be seen as an endorsement of this vision.

It is nevertheless salient to consider that scenario modelling suggests the localist aspirations expressed by many of the respondents are extremely difficult to realize (Verkerk et al. 2016; Brown et al. 2016). Current policies promote efficiency, specialization and competition, which generally drive large-scale food production in the most favourable locations. But despite these challenges there are trends towards greater local multifunctionality, e.g. for urban food production, green and blue infrastructure and agricultural diversification. These developments generally require government intervention (incentives, regulation), and the results from the societal statements (Fig. 4c) suggest public support from the younger generation.

Finally, it must be noted that from a sustainability perspective the respondents' desires are contradictory. A significant group (Clusters 1 and 2, i.e. 63\% of respondents) clearly envisages a more sustainable future, evidenced by choices to live in eco-friendly homes, change their diet and cycle to work. But distant travel remains popular, and the desire for a detached house with a garden will compete for space with parks and local agriculture. Furthermore, the strong wish to mainly eat organic or extensively produced food will likely increase land demand, much of which may be 'exported' to other parts of the world (Tuomisto et al. 2012). This reflects the land sharing/land sparing debate (Phalan et al. 2011), with respondents showing a preference to land sharing, but are likely unaware of potential negative consequences.

This paper presents a first attempt to use crowdsourcing to understand citizen visions for their lives in the future. Results are insightful, but the geographic bias and modest response calls for an expanded study, which could also focus more strongly on the trade-offs identified here. Focused national or regional studies could also increase participation and allow results to be compared to policy visions. Finally, the methodology presented here would be well suited to support education curricula and could help introduce land use-related sustainability challenges to young people in a meaningful way.

\section{Conclusions}

This study has demonstrated how crowdsourcing can be used to better understand how the general public wants to live in the future. The methodology worked well, and the sample seemed reasonably representative albeit skewed towards an educated population. Results show a strong desire for change, and for more sustainable lifestyles. There is desire for local and ecologically friendly food production, to eat less meat, to have access to green infrastructure and the ability to cycle to work. However, international travel remains popular, and the desire for extensive food production and owning detached houses with gardens will likely result in complex land use tradeoffs. Future work could focus more specifically on quantifying these trade-offs, and informing respondents about the consequences of their lifestyle choices. This was a first attempt to use crowdsourcing to understand citizen visions for their lives in the future, and our lessons learned will 
help future studies improve representativeness and increase responses.

Acknowledgements This research was funded by the European Commission under the Seventh Framework Programme Grant Agreement No. 265104-Visions on Land Use Transitions in Europe (VOLANTE; www.volante-project.eu). We wish to thank all 1131 participants of the survey, and the 70 students who helped test the software for their collaboration. We thank Scriberia (www.scriberia. co.uk) for the images used in the experiment.

Open Access This article is distributed under the terms of the Creative Commons Attribution 4.0 International License (http://creative commons.org/licenses/by/4.0/), which permits unrestricted use, distribution, and reproduction in any medium, provided you give appropriate credit to the original author(s) and the source, provide a link to the Creative Commons license, and indicate if changes were made.

\section{References}

Aldred R, Jungnickel K (2014) Why culture matters for transport policy: the case of cycling in the UK. J Transp Geogr 34:78-87. doi:10.1016/j.jtrangeo.2013.11.004

Anderlucci L, Hennig C (2014) The clustering of categorical data: a comparison of a model-based and a distance-based approach. Commun Stat Theory Methods 43:704-721. doi:10.1080/ 03610926.2013.806665

Bateman IJ, Harwood AR, Mace GM, Watson RT, Abson DJ, Andrews B, Binner A, Crowe A, Day BH, Dugdale S, Fezzi C, Foden J, Hadley D, Haines-Young R, Hulme M, Kontoleon A, Lovett AA, Munday P, Pascual U, Paterson J, Perino G, Sen A, Siriwardena G, Van Soest D, Termansen M (2013) Bringing ecosystem services into economic decision-making: land use in the United Kingdom. Science 341:45-50. doi:10.1126/science. 1234379

Beilin R, Lindborg R, Stenseke M, Pereira HM, Llausàs A, Slätmo E, Cerqueira Y, Navarro L, Rodrigues P, Reichelt N, Munro N, Queiroz C (2014) Analysing how drivers of agricultural land abandonment affect biodiversity and cultural landscapes using case studies from Scandinavia, Iberia and Oceania. Land Use Policy 36:60-72. doi:10.1016/j.landusepol.2013.07.003

Bin S, Dowlatabadi H (2005) Consumer lifestyle approach to US energy use and the related $\mathrm{CO}_{2}$ emissions. Energy Policy 33:197-208. doi:10.1016/S0301-4215(03)00210-6

Blake MK, Mellor J, Crane L (2010) Buying local food: shopping practices, place, and consumption networks in defining food as "Local". Ann Assoc Am Geogr 100:409-426. doi:10.1080/ 00045601003595545

Branca G, Lipper L, McCarthy N, Jolejole MC (2013) Food security, climate change, and sustainable land management. A review. Agron Sustain Dev 33:635-650. doi:10.1007/s13593-013-0133-1

Brown E, Dury S, Holdsworth M (2009) Motivations of consumers that use local, organic fruit and vegetable box schemes in Central England and Southern France. Appetite 53:183-188. doi:10. 1016/j.appet.2009.06.006

Brown C, Holzhauer S, Metzger MJ, Paterson J, Rounsevell M (2016) Land managers' behaviours modulate pathways to visions of future land systems. Reg Environ Change doi:10.1007/s10113-016-0999-y

Chu S, Majumdar A (2012) Opportunities and challenges for a sustainable energy future. Nature 488:294-303. doi:10.1038/ nature 11475

Commission European (2011) The EU biodiversity strategy to 2020. European Commission, Luxembourg de Boer J, Helms M, Aiking H (2006) Protein consumption and sustainability: diet diversity in EU-15. Ecol Econ 59:267-274. doi:10.1016/j.ecolecon.2005.10.011

de Vries M, de Boer IJM (2010) Comparing environmental impacts for livestock products: a review of life cycle assessments. Livest Sci 128:1-11. doi:10.1016/j.livsci.2009.11.007

Dickinson JL, Zuckerberg B, Bonter DN (2010) Citizen science as an ecological research tool: challenges and benefits. Annu Rev Ecol Evol Syst. doi:10.1146/annurev-ecolsys-102209-144636

EC (2012) Europeans and their Languages. Special Eurobarameter 386 of the European Commission datasets https://data.europa.eu/euodp/ en/data/dataset/S1049_77_1_EBS386 Accessed 5 Aug 2016

Estelles-Arolas E, González-Ladrón-de-Guevara F (2012) Towards an integrated crowdsourcing definition. J Inf Sci 38:189-200. doi: $10.1177 / 0165551512437638$

Eurostat (2016a) Statistics on European cities. http://ec.europa.eu/ eurostat/statistics-explained/index.php/Statistics_on_European_ cities Accessed 5 Jan 2016

Eurostat (2016b) Europe 2020 indicators-education. http://ec. europa.eu/eurostat/statistics-explained/index.php/Europe_2020_ indicators_-_education Accessed 5 Jan 2016

Evans L, Maio GR, Corner A, Hodgetts CJ, Ahmed S, Hahn U (2013) Self-interest and pro-environmental behaviour. Nat Clim Change 3:122-125. doi:10.1038/nclimate 1662

Gerbens-Leenes PW, Nonhebel S (2002) Consumption patterns and their effects on land required for food. Ecol Econ 42:185-199. doi:10.1016/S0921-8009(02)00049-6

Gimona A, Poggio L, Polhill JG, Castellazzi M (2015) Habitat networks and food security: promoting species range shift under climate change depends on life history and the dynamics of land use choices. Landsc Ecol 30:771-789. doi:10.1007/s10980-0150158-8

Gössling S, Peeters P (2007) 'It does not harm the environment! An analysis of industry discourses on tourism, air travel and the environment. J Sustain Tour 15:402-417. doi:10.2167/jost672.0

Harvey M, Pilgrim S (2011) The new competition for land: food, energy, and climate change. Food Policy 36:S40-S51. doi:10. 1016/j.foodpol.2010.11.009

Henrich J, Heine SJ, Norenzayan A (2010) The weirdest people in the world? Behav Brain Sci 33:61-83. doi:10.1017/ S0140525X0999152X

Hoekstra AY, Wiedmann TO (2014) Humanity's unsustainable environmental footprint. Science 344:1114-1117. doi:10.1126/ science. 1248365

Hofmann M, Westermann JR, Kowarik I, Van der Meer E (2012) Perceptions of parks and urban derelict land by landscape planners and residents. Urban Forest Urban Green 11:303-312. doi:10.1016/j.ufug.2012.04.001

Howe J (2008) Crowdsourcing: why the power of the crowd is driving the future of business. Crown Publishing Groupe, New York

Hsieh HF, Shannon SE (2005) Three approaches to qualitative content analysis. Qual Health Res 15:1277-1288. doi:10.1177/ 1049732305276687

Kaufman L, Rousseeuw PJ (1990) Finding groups in data. An introduction to cluster analysis. Wiley Series in probability and mathematical statistics. Applied probability and statistics. Wiley, New York

Kazai G (2011) In search of quality in crowdsourcing for search engine evaluation. Lect Notes Comput Sci 6611:165-176. doi:10.1007/978-3-642-20161-5_17

Lawler JJ, Lewis DJ, Nelson E, Plantinga AJ, Polasky S, Withey JC, Helmers DP, Martinuzzi S, Pennington D, Radeloff VC (2014) Projected land-use change impacts on ecosystem services in the USA. Proc Natl Acad Sci 111:7492-7497. doi:10.1073/pnas. 1405557111 
Lee JJ, Lukachko SP, Waitz IA, Schafer A (2001) Historical and future trends in aircraft performance, cost, and emissions. Annu Rev Energy Environ 26:167-200. doi:10.1146/annurev.energy.26.1.167

Maraja R, Jan B, Teja T (2016) Perceptions of cultural ecosystem services from urban green. Ecosyst Serv 17:33-39. doi:10.1016/ j.ecoser.2015.11.007

Mozaffarian D, Afshin A, Benowitz NL, Bittner V, Daniels SR, Franch HA, Jacobs DR, Kraus WE, Kris-Etherton PM, Krummel DA, Popkin BM, Whitsel LP, Zakai NA (2012) Population approaches to improve diet, physical activity, and smoking habits: a scientific statement from the American heart association. Circulation 126:1514-1563. doi:10.1161/CIR. 0b013e318260a20b

Murray-Rust D, Brown C, van Vliet J, Alam SJ, Robinson DT, Verburg PH, Rounsevell M (2014a) Combining agent functional types, capitals and services to model land use dynamics. Environ Model Softw 59:187-201. doi:10.1016/j.envsoft.2014.05.019

Murray-Rust D, Houtkamp J, Metzger M, La Riviere I, Pérez-Soba M, Paterson J, Jensen A (2014b) A grapahic novel based approach A graphic novel based approach to large scale elicitation of normative future scenarios. CrowdUI 2014-1st International Workshop on User Interfaces for Crowdsourcing and Human Computation, Como (Italy) doi: 10.13140/ RG.2.1.2478.1843

Noy C (2008) Sampling knowledge: the hermeneutics of snowball sampling in qualitative research. Int $\mathrm{J}$ Soc Res Methodol 11:327-344. doi:10.1080/13645570701401305

NVivo (2012) Qualitative data analysis Software. QSR International Pty Ltd. Version 10

Padel S, Foster C (2005) Exploring the gap between attitudes and behaviour: understanding why consumers buy or do not buy organic food. $\mathrm{Br}$ Food $\mathrm{J}$ 107:606-625. doi:10.1108/ 00070700510611002

Palmer JC, Strickland J (2016) A beginners guide to crowdsourcingstrengths, limitations and best practice for psychological research. Psychological Science Agenda June 2016 http://www. apa.org/science/about/psa/2016/06/changing-minds.aspx Accessed 9 Aug 2016

Palomo I, Martín-López B, Zorrilla-Miras P, García Del Amo D, Montes C (2014) Deliberative mapping of ecosystem services within and around Doñana National Park (SW Spain) in relation to land use change. Reg Environ Change 14:237-251. doi:10. 1007/s10113-013-0488-5

Peloza J, White K, Shang J (2013) Good and guilt-free: the role of self-accountability in influencing preferences for products with ethical attributes. J Mark 77:104-119. doi:10.1509/jm.11.0454

Pérez-Soba M, Paterson J, Metzger M (2015). Visions of future land use in Europe: stakeholder visions for 2040. VOLANTE project report, Alterra Wageningen UR, 24 pp. http://www.volanteproject.eu/docs/visions.pdf Accessed 25 Jan 2016

Pérez-Soba M, Paterson J, Metzger MJ, Gramberger M, Houtkamp J, Jensen A, Murray-Rust D, Verkerk PJ (2016) Imagining a sustainable land use in Europe: stakeholder visions to support decision making. Reg Environ Change (submitted)

Phalan B, Onial M, Balmford AJ, Green RE (2011) Reconciling food production and biodiversity conservation: land sharing and land sparing compared. Science 333:1289-1291. doi:10.1126/science. 1208742

Pimentel D, Pimentel M (2003) Sustainability of meat-based and plant-based diets and the environment. Am J Clin Nutr 78:660-663

Plieninger T, Bieling C, Ohnesorge B, Schaich H, Schleyer C, Wolff F (2013) Exploring futures of ecosystem services in cultural landscapes through participatory scenario development in the Swabian Alb, Germany. Ecol Soc. doi:10.5751/ES-05802180339
Rounsevell MDA, Pedroli B, Erb K-H, Gramberger M, Busck AG, Haberl H, Kristensen S, Kuemmerle T, Lavorel S, Lindner M, Lotze-Campen H, Metzger MJ, Murray-Rust D, Popp A, PérezSoba M, Reenberg A, Vadineanu A, Verburg P, Wolfslehner B (2012) Challenges for land system science. Land Use Policy 29:899-910. doi:10.1016/j.landusepol.2012.01.007

Sachdeva S, Jordan J, Mazar N (2015) Green consumerism: moral motivations to a sustainable future. Curr Opin Psychol 6:60-65. doi:10.1016/j.copsyc.2015.03.029

Schwanen T, Banister D, Anable J (2012) Rethinking habits and their role in behaviour change: the case of low-carbon mobility. J Transp Geogr 24:522-532. doi:10.1016/j.jtrangeo.2012.06.003

Scoccia D (2013) The right to autonomy and the justification of hard paternalism. In: Coons C, Weber M (eds) Paternalism: theory and practice. Cambridge University Press, Cambridge, pp 74-92

Skea J, Nishioka S (2008) Policies and practices for a low-carbon society. Clim Policy 8:S5-S16. doi:10.3763/cpol.2008.0487

Smith P (2013) Delivering food security without increasing pressure on land. Global Food Secur 2:18-23. doi:10.1016/j.gfs.2012.11. 008

Stone B Jr (2009) Land use as climate change mitigation. Environ Sci Technol 43:9052-9056. doi:10.1021/es902150g

Sunstein CR (in press) Nudging and choice architecture: ethical considerations. Yale J Regul 32(2). http://papers.ssrn.com/sol3/ papers.cfm?abstract_id=2551264\#\# Accessed 25 Jan 2016

Thaler RH, Sunstein CR (2008) Nudge: Improving decisions about health, wealth and happiness. Yale University Press, New Haven

Tuomisto HL, Hodge ID, Riordan P, Macdonald DW (2012) Does organic farming reduce environmental impacts?-A meta-analysis of European research. J Environ Manag 112:309-320. doi:10.1016/j.jenvman.2012.08.018

Turečková K, Martinát S (2015) Quarternary sector and extended sectoral structure of the economy in the selected European countries. Working Paper in Interdisciplinary Economics and Business Research no. 10. Silesian University in Opava, School of Business Administration in Karviná. https://ideas.repec.org/p/ opa/wpaper/0010.html Accessed 5 Jan 2016

Tzoulas K, Korpela K, Venn S, Yli-Pelkonen V, Kaźmierczak A, Niemela J, James P (2007) Promoting ecosystem and human health in urban areas using Green Infrastructure: a literature review. Landsc Urban Plan 81:167-178. doi:10.1016/j.land urbplan.2007.02.001

Urry J (2012) Changing transport and changing climates. J Transp Geogr 24:533-535. doi:10.1016/j.jtrangeo.2012.05.005

van den Haak MJ, de Jong MDT, Schellens PJ (2003) Retrospective versus concurrent think-aloud protocols: testing the usability of an online library catalogue. Behav Inf Technol 22:339-351. doi:10.1080/0044929031000

Vandenbergh MP, Steinemann AC (2007) The carbon-neutral individual. New York Univ Law Rev 82:1673-1745

Westhoek H, Lesschen JP, Rood T, Wagner S, De Marco A, MurphyBokern D, Leip A, van Grinsven H, Sutton MA, Oenema O (2014) Food choices, health and environment: effects of cutting Europe's meat and dairy intake. Global Environ Change 26:196-205. doi:10.1016/j.gloenvcha.2014.02.004

Verkerk PJ, Lindner M, Pérez-Soba M, Paterson JS, Helming J, Verburg PH, Kuemmerle T, Lotze-Campen H, Moiseyev A, Müller D, Popp A, Schulp CJE, Stürck J, Tabeau A, Wolfslehner B, van der Zanden EH (2016) Identifying pathways to visions of future land use in Europe. Reg Environ Change. doi:10.1007/ s10113-016-1055-7

Zapico JL, Turpeinen M, Brandt N (2009) Climate persuasive services: changing behavior towards low-carbon lifestyles. In: Proceedings of the 4th international conference on persuasive technology, New York, NY doi:10.1145/1541948.1541968 